\title{
Entrepreneurial Game Theoretic Approach to Planning Flexibility and Environmental Scanning
}

\author{
Owolabi L. Kuye $^{1}$, Bankole Abiola ${ }^{2} \&$ Ben E. A. Oghojafor ${ }^{1}$ \\ ${ }^{1}$ Department of Business Administration, University of Lagos, Lagos State, Nigeria \\ ${ }^{2}$ Department of Actuarial Science and Insurance, University of Lagos, Lagos State, Nigeria \\ Correspondence: Owolabi L. Kuye, Department of Business Administration, University of Lagos, Lagos State, \\ Nigeria. E-mail: labikuye@yahoo.com
}

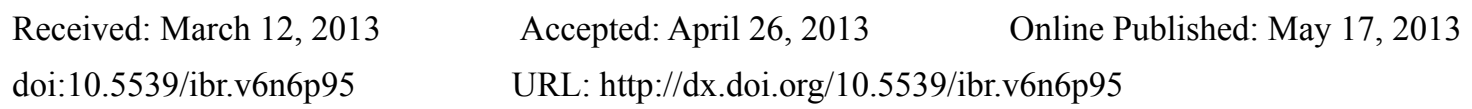

\begin{abstract}
This study focuses on planning flexibility and environmental scanning from the standpoint of corporate entrepreneurship, as represented by Top management. Game theory was applied in this study. In doing this, the problem was viewed from a "worst case design concept" which can be summarised as follows: The intrapreneur (the entrepreneur within a firm or corporate entrepreneurs) wishes to minimise the cost of operation while the environment tries to maximize the cost of operation. Hence, we introduce a cost functional, which is the cost of risk faced by the intrapreneur. We assume that the entrepreneur can apply flexibility in planning, hence denote this as control, while the environment that is needed to be scanned is denoted as uncertainty. The model of game is applied to allow for saddle point (a point where there is no 'gain' no 'loss') solution. The implication of this is that for a saddle point to exist in a "worst case" situation, the intrapreneur is likely to breaking-even. Thus, a proper mathematical treatment is given for such a game problem.
\end{abstract}

Keywords: entrepreneurial, intrapreneur, corporate entrepreneurship, planning flexibility, environmental scanning, game theory, saddle point

\section{Introduction}

Practitioners and scholar have recognised the challenges of pursuing entrepreneurship within an organisation (Mair \& Rata, 2004) in the face of environmental uncertainty. Many entrepreneurship literature are of the view that it is necessary to promote entrepreneurial attitude and activities in firms (Lumpkin \& Dess, 1996; Covin \& Slevin, 1991; Zahra, 1993).

For firms to become entrepreneurial and enhance their performance in the light of changing business environment, it is important that they employ planning flexibility as a strategy (Li et. al., 2006). Top management also needs to consider environmental scanning to be able to adopt planning flexibility. Environmental scanning can encourage entrepreneurial behaviour of firms in terms of taking risk, being proactive and innovative. The ability of firms to cope with uncertainty and behave entrepreneurially is a function of the intensity of their scanning efforts (Oghojafor et al., 2009).

\section{Literature Review}

\subsection{Planning Flexibility}

Many firms are finding it difficult to rely on rigid rules, routines, and structures that have the key characteristics of bureaucracy and formal organisation. In recent times, firms are increasingly required to respond flexibly to diverse needs of various stakeholders (employees, customers, creditors, suppliers, distributors, shareholders and communities) in a manner that does not cause injustice and unfairness (Ancona et al., 2005).

Firms operate in environments where the rate of change is increasing. These environments place demand on the ability of the organisation to change. Because of the rapidity of change that takes place in the environments, firms should be flexible in their approach to planning to enhance their productivity. Planning flexibility results from the capability of a firm's strategic plan to adjust as environmental opportunities and threats emerge (Li et al., 2006). Flexible planning brings about proactiveness, creativity and innovativeness. Accordingly, it promotes a high degree of corporate entrepreneurship (Barringer \& Bluedorn, 1999). 


\subsubsection{The Need for Planning Flexibility}

Kukalis (1989) in Kemelgor (2002) suggests the need for firms in a rapidly changing business environment to adopt flexible planning. He also opined that firms in this situation will enhance their performance, if only they can employ planning flexibility approach. According to Alpkan et al. (2007), flexible planning involves the capacity of a firm's strategic plans to become adaptive and responsive to change when necessary. Bhalla et al. (2006) opine that without flexibility in planning, rigidity in planning may be counterproductive in the long-run.

Planning is critical to the systematic growth and adaptation of a firm in a changing environment (Heimann \& Lusk, 1976). The authors believed that this is true of firms in all sectors. Inherently in the planning process is the consideration of uncertainty concerning future events. That uncertainty may include not only the occurrences of future states of nature but also the availabilities of future decision alternatives. Recognising the problem of uncertainty in the planning process, managers in actual practice and researchers in the development of decision models have mentioned the need for considering the flexibility of a plan, as a criterion for selecting a course of action in a planning process (Heimann \& Lusk, 1976).

According to Ancona et al. (2005), the need for flexibility is driven by intensifying competition so that capabilities for tailoring products and services to a range of customer needs are increasingly a source of competitive advantage.

\subsubsection{Decision on Flexibility}

As part of its strategic thinking, an organisation should consider whether it is imperative to increase its flexibility and if so, which approach is the most appropriate and effective (Aaker \& Mascarenhas, 1984). The authors identified a series of four steps that can help address these dimensions:

1) Identifying environmental changes: This first step involves a careful external focusing on the potential environmental changes confronting the firm. They may include competitor threats, technological breakthroughs, political events, changes in cultural values and behaviours, or economic in development. They could also be highly specific like the development of a particular type and size of cell- phone memory.

2) Appraising likely environmental changes: That is, consideration of the size, likelihood, and nature of the effect of each environmental change upon the firm. There will always be a large number of potential environmental changes. It is necessary to reduce them to a manageable number or at least to prioritise them.

3) The flexibility option: This step considers the flexibility option for each identified and screened environmental change. Flexibility needs to be considered in the context of a particular potential environmental change. The problem is that one approach might increase flexibility with respect to one potential environmental change but decrease it with respect to another. For instance, inventory might be used to buffer production uncertainties and fluctuations in sales and supplies. However, a technological change could cause the product to become obsolete leading to inventory not easily liquidated.

4) Other methods for coping with environmental changes: Flexibility is expected to be the most cost-effective technique for coping with environmental change and uncertainty. Other techniques too can be considered in addition to or in conjunction with flexibility: contingency planning, insurance, control, avoidance, and prediction.

\subsection{Environmental Scanning}

Creating and managing a successful business or venture requires research and planning. According to Sawyer (1993), research has revealed several reasons for the differences between planning in developed economies and less developed economies. Such reasons are attributable to dearth of the required technology required to scan and collect necessary data from the environment, and lack of information sources and other infrastructures for performing scanning activities (Sawyer, 1993).

Consequently, organisations, profit and non-profit, are faced with challenges for survival and economic success. However, it should be noted that success results only when a firm strategically understands the external factors so as to be able to respond appropriately in a manner that will guarantee the firm's survival and sustainable success. Environmental scanning is a means of gaining this understanding (Albright, 2004). For instance, business opportunities are daily springing up in all the sectors of the Nigerian economy as the nation's population increases and new communities are established (Awaiko, 2004). To discover these business opportunities, environmental scanning is necessary.

Scanning has to do with the gathering and utilisation of information concerning trends and events occurring in the external environment of a firm. It refers to awareness creation and communication of issues in the external environment that may likely affect the way a firm makes decisions (Albright, 2004). According to Choo (2001), environmental scanning could range from an informal conversation with someone to a formal business research 
activity. Environmental scanning includes the actions taken to seek information in a firm's external environment relating to trends and events, the awareness of which would assist senior management concerning the futurity of the firm's current decisions (Aguilar, 1967 in Kourteli, 2005). Scanning intensity is the degree of comprehensiveness of the environmental scanning process and the effort towards the activities involved in scanning the environment (Barringer \& Bluedorn, 1999).

Owualah (1999) asserts that the trends that need to be scanned are rooted in five macro environments: economic, social, technological, competitive and legal environments. Elenkov (1997) contests that the environments that need to be scanned can be classified into two layers. The first, which is closest to the organisation, is referred to as the task environment. Its elements include investors, employees, customers, suppliers, creditors, distributors, competitors and regulatory agencies. The second is the general environment. It refers to those factors that influence firms indirectly. The general environment includes socio-cultural, economic, and legal-political factors. The information gathered during scanning is provided to key managers within the firm and is used to guide management in future plans. It is also a means of assessing a firm's strengths and weaknesses in response to external threats and opportunities. Thus, environmental scanning is a tool for identifying, collecting, and translating information about external influences into useful plans and decisions (Albright, 2004).

\subsubsection{Why the Business Environment Should Be Scanned}

Firms need to do environmental scanning for the followings reasons:

Environmental scanning is done so that firms are aware of the forces affecting change in the external environment in order to develop the strategies to sustain or enhance their competitiveness in the future (Choo, 2001).

As a result of changes and uncertainties in the global environment and recently new business practices, firms can easily lag behind by not keeping up with new technology, current regulations, and various growing trends. Environmental scanning leads to greater anticipatory management (Albright, 2004) as it provides an awareness of the changing environment.

According to Albright (2004), environmental scanning makes it possible for a firm to deal with external environmental issues that may, otherwise, have been difficult to identify. It is not just about information gathering; rather, its purpose is to focus on future impacts and potential influences on the organisation and how it can respond strategically (Albright, 2004).

Environmental scanning enables a firm to highly focus on information from the external environment, as this will assist top management to become accessible to various sources that will assist them in their strategic planning and problem-solving situations (Popoola, 2001).

Environmental scanning should be constantly done in order to be anticipatory and adaptive to changes in the environment. Through constant monitoring of the external environment, it is easier for top management to respond to environmental change by making necessary adjustments in the light of the change. Hence, suggesting the difference between success and failure (Albright, 2004).

\subsection{Corporate Entrepreneurship}

Entrepreneurship can be referred to as the process by which individuals, spurred by the desire for personal satisfaction or some rewards, act differently by adding value to an already existing venture or create an entirely new one not minding the risk involved (Kuye, 2008). Entrepreneurship includes the unique ability and determination to identify and exploit opportunity to create something new in the world (Martin \& Osberg, 2007).

Corporate entrepreneurship is entrepreneurship activities within an existing organisation which has been recognised as that which fosters economic prosperity, organisational performance, and wealth creation (Antoncic \& Hisrich, 2004; Antoncic \& Zorn, 2004). Corporate entrepreneurship is concerned with the development and sustainability of new ventures within an established firm (Garvin \& Lavesque, 2006).

\subsubsection{Entrepreneurial Postures}

There are three postures or dimensions (risk-taking, proactiveness and innovativeness) of entrepreneurial orientation as conceptualised by Kreiser et al. (2002); Moris et al. (2006); Chow (2006); Wiklund and Shepherd (2005); Covin and Sleving (1989).

Innovation: Innovation is the process of adding value to a total firm, its employees, suppliers and customers via the creation of new techniques, procedures, services, products and marketing strategies (Shaw, O'Loughlin \& McFadzean, 2005).

Risk-taking: According to Dess \& Lumpkin (2005), risk-taking is the ability of a firm's willingness to get involved 
in a venture and act courageously without regards to the likelihood of the venture's success or failure.

Proactiveness: Proactiveness is the process by which a firm continuously and actively searches rather than passively wait for market opportunities in view of the changing environment (Venkatraman, 1989).

Even though, entrepreneurs are critical to economic development, developing countries especially in the Sub-Sahara Africa are yet to develop the wherewithal to exploit this resource (Bawuah, Buame \& Hinson, 2006).

\section{Methodology}

We let $x(t)$ represent the state of corporate entrepreneurship at any time $t$, and let $u(t)$ represent planning flexibility which is the control exerted by the top management in case there is a deviation from the original plan occasioned by environmental scanning. Also we let $v(t)$ represent environmental scanning at any time $t$. For mathematical tractability; we model the problem on real Hilbert Space, as defined below:

Mathematical Fundamentals: Consider a differential game modeled on Hilbert Spaces. Specifically, let $H_{i}, i=1,2,3$ be real Hilbert spaces.

Consider a differential game defined by:

$$
\begin{gathered}
x^{\prime}(t)=A x(t)+B u(t)+C v(t) \\
x(0)=x_{0} \in H_{1}
\end{gathered}
$$

We associate a cost functional to equations (1) and (2), and define it as

$$
J(u, v)=\int_{0}^{T}\{<x(t), Q x(t)>+<u(t), R u(t)>+<v(t), W v(t)>\} d t
$$

Where we let $\langle$.$\rangle and \|$.$\| denote inner product and norm respectively on H_{i}, i=1,2,3, x(t)$ represent the state vector in $H_{1}, u(t)$ is the control strategy for player 1, with values in $H_{2}$ and $v(t)$ is the control strategy for player 2, with values in $\mathrm{H}_{3}$.

\section{Remark (1):}

(i) It is in order, at this point, to explain that player 1 represents the intrapreneur who uses all efforts including factors of production to carryout production processes employing environmental scanning strategy $u(t)$ at any time $\mathrm{t}$ to counteract measures that would make him deviate from the original plan.

(ii) The environment in which the intrapreneur operates also employs strategy $v(t)$ to indirectly work against the efforts of player1 (intrapreneur). Hence in this paper we regard the environment as the player 11.

(iii) The cost functional $J(u, v)$ defined in (3) is the cost of the risk faced by the intrapreneur which must be minimized, but may be maximized by the environmental uncertainties if the intrapreneur fails to apply correct environmental scanning.

$A$ is a linear operator in $H_{1}$ with $D_{A}$ (domain of A) dense in $H_{1} . A$ is a closed operator.

The resolvent: $R(\rho, A)=1 /(\rho I-A)$ exist if $\operatorname{Re} \rho \leq 0$ and $|R(\rho, A)| \leq k / 1+|\rho|$.

The operators: B: $H_{2} \rightarrow H_{1}$ and $C: H_{3} \rightarrow H_{1}$ are linear and uniformly bounded on [0,T]. The operator $Q$ on $H_{1}$ is self-adjoint, symmetric and non-negative definite.

$R$ and $R^{-1}$ on $\mathrm{H}_{2}$ are self adjoint symmetric and positive definite, while $W$ and $W^{-1}$ are self adjoint and negative definite. Player 1 apply strategy $u(t)$ at time $t$ to minimize $J(u, v)$ and player 2 apply strategy $v(t)$ at time $t$ to maximize $J(u, v)$.

Remark (2): The above explanations are necessary to ensure that the game proposed guaranteed existence of solution and mathematically solvable.

Given that $J(\bar{u}, \bar{v})$ is the optimal solution of $J(u, v)$, then the main problem is to show that:

$$
J(\bar{u}, v) \leq J(\bar{u}, \bar{v}) \leq J(u, \bar{v})
$$

We start achieving this aim by defining the Hamiltonian of the equation (1), (2) and (3) as follows:

$$
H(x, u, v, \lambda)=<x(t), Q x(t)>+<v(t), W v(t)>+\lambda^{T}[A x(t)+B u(t)+C v(t)]
$$




\section{Assumptions:}

A1: The pay-off functional can be expressed as follows: There exist $Q_{1}, Q_{2}$ such that $Q=\left[Q_{1}, Q_{2}\right]$ and,

A2: The controls $u(t)$ and $v(t)$ are separated on the right hand side of (1) i.e there exist $A_{1}, A_{2}$ such that $A=\left[A_{1}, A_{2}\right]$

$\mathrm{A} 3: \bar{\lambda}^{\prime}=-H_{x}(\bar{x}, \bar{u}, \bar{v}, \bar{\lambda})$

A4: $\bar{\lambda}(T)=0$

A5: $H_{u}(\bar{x}, \bar{u}, \bar{v}, \bar{\lambda})=0$

A6: $H_{v}(\bar{x}, \bar{u}, \bar{v}, \bar{\lambda})=0$

\section{The Multiplier}

We now set

$$
\lambda=\left(\begin{array}{l}
\beta \\
\eta
\end{array}\right)
$$

$\lambda($.$) is the multiplier, while \beta($.$) and \eta($.$) will be specified later.$

We transform (1)-(3) into unconstrained problem by introducing a penalty constant $\mu($.$) to get:$

Problem 1: Minimax

$$
\begin{gathered}
J(x, u, v, \mu, \lambda)=J(u)+J(v)+\mu \int_{0}^{T}\left\|x^{\prime}(t)-A_{1} x(t)-B u(t)\right\|^{2} d t+\mu \int_{0}^{T}\left\|x^{\prime}(t)-A_{2} x(t)-C v(t)\right\|^{2} d t+ \\
\int_{0}^{T}<\beta, x^{\prime}(t)-A_{1} x(t)-B u(t)>d t+\int_{0}^{T}<\eta, x^{\prime}(t)-A_{2} x(t)-C v(t)>d t
\end{gathered}
$$

For computational convenience, we can update $\beta$ and $\eta$ as follows:

$$
\begin{aligned}
& \beta_{k+1}(t)=\beta_{k}(t)+2 \alpha \mu\left[x_{k}^{\prime}(t)-A_{1} x_{k}(t)-B u_{k}(t)\right], \beta_{0}=0, k=0,1,2, \ldots . ., \text { where }, 0 \leq \beta \leq 1 \\
& \eta_{k+1}(t)=\eta_{k}(t)+2 \tau \mu\left[x^{\prime}(t)-A_{2} x_{k}(t)-C v_{k}(t)\right], \eta_{0}=0, k=0,1,2, \ldots, \text { where }, 1 \leq \tau \leq 0
\end{aligned}
$$

Suppose $\beta=\eta=0$ in problem 1 , we have

Problem2: Min max

$$
j(x, u, v, \mu)=J(u)+J(v)+\mu \int_{0}^{T}\left\|x^{\prime}(t)-A_{1} x(t)-B u(t)\right\|^{2} d t+\mu \int_{0}^{T}\left\|x^{\prime}(t)-A_{2} x(t)-C v(t)\right\|^{2} d t
$$

The following result is a consequence of the assumption A1 and A2

Result 1: There exists a saddle point solution $(\bar{x}, \bar{u} \cdot \bar{v}, \bar{\mu})$ such that problem 2 satisfies

$$
J(\bar{x}, \bar{u}, v, \bar{\mu}) \leq J(\bar{x}, \bar{u}, \bar{v}, \bar{\mu}) \leq J(\bar{x}, u, \bar{v}, \bar{\mu}) .
$$

Our aim is to establish the existence of the saddle point defined in (8).

We shall do this in steps.

Step1. Consider the control problem defined by:

$$
x^{\prime}(t)=A_{1}(t) x(t)+B u(t)
$$

With the pay off functional defined by:

$$
J(x, u)=\int_{0}^{T}\left\{<x(t), Q_{1} x(t)>+<u(t), R u(t)>\right\} d t
$$

Control $u($.$) is selected to minimise the pay off defined in (10)$

The unconstrained equivalence of problem (9) and (10) is given as:

$$
J(x, u, \mu)=\int_{0}^{T}\left\{<x(t), Q_{1} x(t)>+<u(t), R u(t)+\mu\left\|x^{\prime}(t)-A_{1} x(t)-B u(t)\right\|^{2}\right\} d t
$$




$$
=\int_{0}^{T}\left\{\begin{array}{l}
<x(t), Q_{1} x(t)>+<u(t), R u(t)>+\mu<x(t), A_{1}^{T} A_{1} x(t)>+\mu<u(t), B^{T} B u(t)>+\mu<x^{\prime}(t), x^{\prime}(t)> \\
-2 \mu<x^{\prime}(t), B u(t)>-2 \mu<x^{\prime}(t), A_{1} x(t)>+2 \mu<x(t), A^{T} B u(t)>
\end{array}\right\} d t
$$

We can put (12) in a quadratic form as defined below:

$$
J(x, u, \mu)=\int\left(\begin{array}{lll}
x & x^{\prime} & u
\end{array}\right)\left(\begin{array}{ccc}
Q_{1}+\mu A_{1}^{T} A & -\mu A_{1} & \mu A_{1}^{T} B \\
-\mu A_{1} & \mu I & -\mu B \\
\mu A_{1}^{T} B & -\mu B & R+\mu B^{T} B
\end{array}\right)\left(\begin{array}{l}
x \\
x^{\prime} \\
u
\end{array}\right) d t
$$

In a compact form, we can write (13) as:

$$
\begin{gathered}
\int_{\Omega}\left\{(w)^{T} \mathrm{H}(w)\right\} d t \\
\text { Where } \Omega=[0, T] \text { and } \mathrm{H}=\left[\begin{array}{ccc}
Q_{1}+\mu A_{1}^{T} A_{1} & -\mu A_{1} & \mu A_{1}^{T} B \\
-\mu A_{1} & \mu I & -\mu B \\
\mu A_{1}^{T} B & -\mu B & R+\mu B^{T} B
\end{array}\right], \\
w^{T}=\left(\begin{array}{lll}
x, & x^{\prime}, & u
\end{array}\right)
\end{gathered}
$$

(Ibiejugba \& Onumanyi 1984), had earlier established that if $m$ and $M$ are the greatest lower bound and the least upper bound of the spectrum of operator $\mathrm{H}$ then at $n t h$ level of iteration, the rate of convergence is given as:

$$
J\left(x_{n}, u_{n}, \mu\right) \leq\left(\frac{1-\frac{m}{M}}{1+\frac{m}{M}}\right)^{2 n} J\left(x_{0}, u_{0}, \mu\right)
$$

Step 2: We will now establish that for $v($.$) a maximizer, at n t h$ level of iteration,

$$
J\left(x_{n}, v_{n}, \mu\right) \geq\left(\frac{1-\frac{m}{M}}{1+\frac{m}{M}}\right)^{2 n} J\left(x_{0}, v_{0}, \mu\right)
$$

To see this, Let $\Omega=[0, T]$ be a fixed interval, denote by $L_{2}\left[\Omega, H_{i}\right]$ the space of Strongly measurable function $z(t) \in H_{i}$ such that:

$$
\int_{\Omega}|z(t)|^{2} d t<\infty
$$

Then $L_{2}\left[\Omega, H_{i}\right]$ is a real Hilbert space with an inner product defined by:

$$
<w, z>=\int_{\Omega}<w(t), z(t)>d t
$$

We now consider a model defined by:

$$
x^{\prime}(t)=A_{2} x(t)+C v(t)
$$

Let $T(t)$ be strongly continuous semi- group generated by $A_{2}$

Consider the functional defined by:

$$
J(x, v)=\int_{0}^{T}\left\{<Q_{2} x(t), x(t)>+<W v(t), v(t)>\right\} d t
$$

W is negative definite, $v(t)$ tries to maximize $J(x, v)$.Transforming (19) and (20) to unconstraint problem we get:

$$
J(x, u, \mu)=\int_{0}^{T}\left\{k x(t), Q_{2} x(t)>+<v(t), W v(t)>+\mu\left\|x^{\prime}(t)-A_{2} x(t)-C v(t)\right\|^{2}\right\} d t
$$


Now, it is easy to note that the mild solution of (19) can be represented as

$$
x(t)=T(t) x_{0}+\int_{0}^{t} T(t-\sigma) C v(\sigma) d \sigma
$$

Define operator $P$ as follows:

$$
(P v)(t)=\int_{0}^{t} T(t-\sigma) C v(\sigma) d \sigma, v \in L_{2}\left[\Omega, H_{3}\right]
$$

Let $T(t) x_{0}=r(t), r(t) \in L_{2}\left[\Omega, H_{1}\right]$, then the corresponding solution to (22) is denoted by:

$$
x(t)=r(t)+(P v)(t)
$$

If we set:

$$
\left\{\begin{array}{l}
Q_{2}+\mu A_{2}^{T} A_{2}=\Theta \\
W+\mu C^{T} C=F \\
A_{2}^{T} P+C=G \\
A_{2}^{T} C=K
\end{array}\right.
$$

Then we can write (21) as:

$$
\frac{J(v, \mu)}{2}=F_{0}+<r(t), L v(t)>+\frac{1}{2}<v(t), \Lambda v(t)>
$$

Where

$$
\begin{gathered}
L=2\left(\Theta^{T} P-\mu A_{2}^{T} C-\mu A_{2}^{T} A_{2}+\mu K\right) \\
\Lambda=F+P^{T} \Theta P-\mu G^{T} G+2 \mu G^{T} A_{2} P+2 \mu K^{T} P \\
F_{0}=\frac{<r(t),\left(\Theta-\mu A_{2}^{T} A_{2}\right) r(t)>}{2}
\end{gathered}
$$

Since $v($.$) is a maximizer of (26) then the operator \Lambda$ must be negative definite, then at nth level of maximization process,

$$
\frac{J\left(v_{n}, \mu\right)}{2} \geq\left[\frac{1-\frac{\bar{m}}{\bar{M}}}{1+\frac{\bar{m}}{\bar{M}}}\right]^{2 n} J_{0}\left(v_{0}, \mu\right)
$$

$\bar{M}$ and $\quad \bar{m}$ denote respectively the least upper and greatest lower bound of the spectrum of the operator $\Lambda$ defined in (28). From (30) three cases are possible namely:

$$
\text { Case I: }\left[\frac{1-\frac{\bar{m}}{\bar{M}}}{1-\frac{\bar{m}}{\bar{M}}}\right]^{2 n}=\left[\frac{1-\frac{m}{M}}{1+\frac{m}{M}}\right]^{2 n}
$$

Then,

$$
J(\bar{v}, \mu) \geq J(\bar{v}, \bar{u}, \mu) \geq J(\bar{u}, \mu)
$$

Case II: $\left[\frac{1-\frac{\bar{m}}{\bar{M}}}{1+\frac{\bar{m}}{\bar{M}}}\right]^{2 n}>\left[\frac{1-\frac{m}{M}}{1+\frac{m}{M}}\right]^{2 n}$

Then,

$$
J(\bar{v}, \mu\} \geq J(\bar{u}, \bar{v}, \mu) \geq J(\bar{u}, \mu)
$$


Case III: $\left[\frac{1-\frac{\bar{m}}{\bar{M}}}{1+\frac{\bar{m}}{\bar{M}}}\right]^{2 n}<\left[\frac{1-\frac{m}{M}}{1+\frac{m}{M}}\right]^{2 n}$

In this case, one can always choose $\bar{v}($.$) such that$

$$
J(\bar{v}, \mu) \geq\left[\frac{1-\frac{m}{M}}{1-\frac{m}{M}}\right]^{2 n} J_{0}\left(v_{0}, \mu\right)
$$

We can infer from all the three cases that:

$$
J(\bar{u}, \mu) \leq J(\bar{u}, \bar{v}, \mu) \leq J(\bar{v}, \mu)
$$

\section{Remark (3)}

(i) The implication of our result is that for entrepreneurial firms, top management through its intrapreneurs requires minimal amount of resources (to do environmental scanning and planning flexibility) in dealing with the risk of entrepreneurship, in the presence of environmental uncertainty.

(ii) The result in (31) represents a worst case situation, that is to say that the intrapreneur will brake-even no matter the situation as long as there is a saddle point as represented in (31).

(iii) It should be very clear that the concept of "uncertainty" is artificial. We just assume that the system behaves according to some law; and model it accordingly. We seek the "best" under a "worst situation" (with respect to the uncertainty) in order to guarantee the desire performance over the entire range of the uncertainty.

\section{Conclusion}

Top management of a firm will pursue an entrepreneurial strategy if it hopes that entrepreneurship can make a notable difference in a firm's ability to compete and achieve sustainable performance (Ramachandran, Devarajan \& Ray, 2006). Then, top management is faced with a lot of challenges, majorly uncertainties, in the business environment that need to be dealt with.

Top management, through its corporate entrepreneurs, wishes to minimise the costs of its operation in the face of uncertainties. It uses the factors of production to provide goods and services which constitute the costs of operation. The environment, on the other hand, tries to maximise these costs via various environmental constraints against the efforts of the top management. For a saddle point to be attained, an effective environmental scanning must be used to plan flexibly to break even.

Top management of an entrepreneurial firm needs to carry out its environmental scanning activities and plan flexibly in a problem-solving manner. This, especially in relation to how innovation activity thrives in the firm and the value of specialised knowledge created is recognised and integrated to create wealth (Ramachandran, Devarajan \& Ray, 2006).

In all of this, planning flexibility and environmental scanning are considered effective strategies that can assist top management to cope with uncertainties in an entrepreneurial environment. Hence, a saddle point is ensured in a "worst case" situation.

\section{References}

Aaker, D. A., \& Mascarenhas, B. (1984). The Need for Strategic Flexibility. Journal of Business Strategy, 5(2), 74-82. http://dx.doi.org/10.1108/eb039060

Abiola, B. (2012). On Generalized Saddle Point Solution for a Class of Differential Games. International Journal of Science and Advanced Technology, 2(8), 27-31.

Aguilar, F. J. (1967). Scanning the Business Environment. New York: Macmillan.

Albright, K. S. (2004). Environmental Scanning: Radar for Success. The Information Management Journal, 38(3), 38-45.

Alpkan, L., Yilmaz, C., \& Kaya, N. (2007). Market Orientation and Planning Flexibility in SMEs: Performance Implications and an Empirical Investigation. International Small Business Journal, 25(2), 152-172. http://dx.doi.org/10.1177/0266242607074518 
Ancona, D., Kochan, T., Maanen, J. V., \& Westney, E. (2005). Managing for the Future: Organisational Behaviour and Processes in MIT Sloan Executive Programmes leading Change in Complex Organisations.

Antoncic, B., \& Hisrich, R. D. (2004). Corporate Entrepreneurship Contingencies and Organisational Wealth Creation. Journal of Management Development, 23(6), 518-550. http://dx.doi.org/10.1108/02621710410541114

Antoncic, B., \& Zorn, O. (2004). The Mediating Role of Corporate Entrepreneurship in the Organisational Support-Performance Relationship: An Empirical Examination. Managing Global Transitions, 2(1), 5-14.

Awaiko, W. J. (2004). Feasibility Report Writing. Lagos: Adeola Printing Press Limited.

Barringer, B. R., \& Bluedorn, A. C. (1999). The Relationship between Corporate Entrepreneurship and Strategic $\begin{array}{lllll}\text { Management. Strategic } & \text { Management }\end{array}$ http://dx.doi.org/10.1002/(SICI)1097-0266(199905)20:5

Bawuah, K., Buame, S., \& Hinson, R. (2006). Reflections on Entrepreneurship Education in African Tertiary Institutions. Acta Commercil, 1-8. http://dx.doi.org /10.4102/ac.v6i1.78

Bhalla, A., Henderson, S., \& Watkins, D. (2006). A Multiparadigmatic Perspective of Strategy. International Small Business Journal, 24(5), 515-537. http://dx.doi.org/10.1177/0266242606067276

Choo, C. W. (2001). Environmental Scanning as Information Seeking and Organisational Learning. Information Research, 7(1). http://dx.doi.org /10.1.1.203.1594

Chow, I. R. (2006). The Relationship between Entrepreneurial Orientation and Firms' Performance in China. SAM Advanced Management Journal, 71(3), 11-21.

Covin, J. G., \& Slevin, D. P. (1989). Strategic Management of Small Firms in Hostile and Benign Environments. Strategic Management Journal, 10(1), 75-87. http://dx.doi.org /10.1002/smj.4250100107

Covin, J. G., \& Slevin, D. P. (1991). A Conceptual Model of Entrepreneurship as Firm Behaviour. Entrepreneurship Theory and Practice, 16(1), 7-25.

Dess, G. G., \& Lumpkin, G. T. (2005). The Role of Entrepreneurial Orientation in Stimulating Effective Corporate

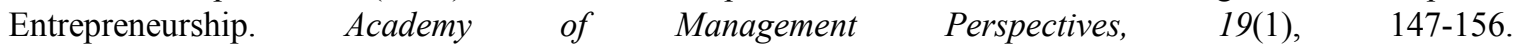
http://dx.doi.org/10.5465/AME.2005.1584

Elenkov, D. S. (1997). Strategic Uncertainty and Environmental Scanning: The Case for Institutional Influences on Scanning Behaviour. Strategic Management Journal, 18(4), 287-302. http://dx.doi.org/10.1002/(SICI)1097-0266

Garvin, D. A., \& Lévesque, L. C. (2006). Meeting the Challenges of Corporate Entrepreneurship. Harvard Business Review, October, 102-112.

Hagen, A., Halle, S., \& Maghrabi, A. (2003). The Impact of the Type of Strategy on Environmental Scanning Activities in the Banking Industry: An International Perspective. IJMC, 13(2), 122-143. http://dx.doi.org/10.1108/eb047469

Heimann, S. R., \& Lusk, E. J. (1976). Health Facility Planning: An Example of a Decision Flexibility Approach. Operational Research Quarterly, 27(2), 449-457. http://dx.doi.org /10.1057/jors.1976.89

Ibiejugba, M. A., \& Onumanyi, P. (1984). On a Control Operator and some of its Applications, Communicated by Professor George Leitmann. Journal of Mathematical Analysis and Applications, 1, 22-32. http://dx.doi.org/10.1016/0022-247X(84)90154-9

Kemelgor, B. H. (2002). A Comparative Analysis of Corporate Entrepreneurial Orientation between Selected Firms in the Netherlands and the U.S.A. Entrepreneurship and Regional Development, 14, 67-87. http://dx.doi.org/10.1080/08985620110087023

Kourteli, L. (2005). Scanning the Business Environment for Information: Evidence from Greece. Information Research, 11(1), 1-12.

Kreiser, P., Marino, L., \& Weaver, K. (2002). Assessing the Psychometric Properties of the Entrepreneurial Orientation Scale: A Multi-country Analysis. Entrepreneurship Theory and Practice, 26(4), 71-94.

Kukalis, S. (1989). The Relationship among Firm Characteristics and Design of Strategic Planning Systems in $\begin{array}{llll}\text { Large Organisations. Journal of } & \text { Management, } & \text { 15(4), }\end{array}$ http://dx.doi.org/10.1177/014920638901500406 
Kuye, O. L. (2009). Entrepreneurship, Strategic Management Practices and Firms' Performance in Manufacturing Firms in Nigeria. (Unpublished Ph.D. Thesis). University of Lagos.

Li, L., Tse, C., \& Gu, B. Y. (2006). The Relationship between Strategic Planning and Entrepreneurial Business Orientation. The Chinese Economy, 39(6), 70-85. http://dx.doi.org /10.2753/CES1097-1475390605

Lumpkin, G. T., \& Dess, G. (1996). Clarifying the Entrepreneurial Orientation Construct and Linking it to $\begin{array}{llll}\text { Performance. Academy of } & \text { Management }\end{array}$ http://dx.doi.org/10.5465/AMR.1996.9602161568

Mair, J., \& Rata, C. (2004). Corporate Entrepreneurship: Linking Strategic Roles to Multiple Dimensions of Performance. IESE Business School WP, 551, 1-21. http://dx.doi.org /10.2139/ssrn

Martin, R. L., \& Osberg, S. (2007). Social Entrepreneurship: The Case for Definition. Standard Social Innovation Review.

Morris, M. H., Allen, J., Schindehutte, M., \& Avila, R. (2006). Balanced Management Control Systems as a Mechanism for Achieving Corporate Entrepreneurship. Journal of Managerial Issues, 18(4), 468-493.

Oghojafor, B. E. A., Kuye, O. L., \& Sulaimon, A. A. (2009). Scanning Intensity and Firms' Performance in the Manufacturing Sector in Nigeria. Journal of Business Research, 3(1\&2), 39-52.

Owualah, S. I. (1999) Entrepreneurship in Small Business Firms. Lagos: G-MAG Investment Ltd.

Popoola, S. O. (2001). Scanning the Environment for Competitive Advantage: A Study of Corporate Banking Managers in Nigeria. Libri, 50, 210-216. http://dx.doi.org/10.1515/LIBR.2000.210

Ramachandran, K., Devarajan, T. P., \& Ray, S. (2006). Corporate Entrepreneurship: How? Vikalpa, 31(1), 85-97.

Sawyer, O. O. (1993). Environmental Uncertainty and Environmental Scanning Activities of Nigerian Manufacturing Executives: A Comparative Analysis. Strategic Management Journal, 14, 287-299. http://dx.doi.org /10.1002/smj.4250140405

Shaw, E., O'Loughlin, A., \& McFadzean, E. (2005). Corporate Entrepreneurship and Innovation Part 2: A Role and Process - based approach. European Journal of Innovation Management, 8(3), 393-408 http://dx.doi.org/10.1108/14601060510627786

Venkatraman, N. (1989). The Concept of Fit in Strategy Research: Toward Verbal and Statistical Correspondence. Academy of Management review, 14(3), 423-444. http://dx.doi.org /10.2307/258177

Wiklund, J., \& Shepherd, D. (2005). Entrepreneurial Orientation and Small Business Performance: A Configurational Approach. Journal of Business Venturing, 20(1), 71-91. http://dx.doi.org/10.1016/j.jbusvent.2004.01.001

Zahra, S. A. (1993). Environment Corporate Entrepreneurship and Financial Performance: A taxonomic approach. Journal of Business Venturing, 8, 319-340. http://dx.doi.org /10.1016/0883-9026(93)90003-N 